\title{
Effect of layer charge on chemical and physical properties of synthetic K-fluorine micas
}

Author's Name

Seiichi TARUTA*, Ryo OBARA, Nobuo TAKUSAGAWA and Kunio KITAJIMA

Author's Affiliation

Department of Chemistry and Materials Engineering, Faculty of Engineering, Shinshu University,

4-17-1, Wakasato, Nagano-shi, Nagano, 380-8553, Japan

*Corresponding Author

Seiichi TARUTA

Department of Chemistry and Materials Engineering, Faculty of Engineering, Shinshu University,

4-17-1, Wakasato, Nagano-shi, Nagano, 380-8553, Japan

TEL: +81-26-269-5416

FAX: +81-26-269-5424

E-mail: staruta@gipwc.shinshu-u.ac.jp 


\section{Abstract}

The fluorine micas (K-fluorine micas; $\mathrm{K}_{X} \mathrm{Mg}_{3-\mathrm{X}} \mathrm{Li}_{\mathrm{X}} \mathrm{Si}_{4} \mathrm{O}_{10} \mathrm{~F}_{2}$ ) having variable layer charges $(x=0.4-1.0)$ were synthesized. The lattice constant $c$ decreased with a decrease in the layer charge while the lattice constants $a$ and $b$ increased. As the layer charge decreased, K-fluorine micas were changed into Na-fluorine micas more rapidly by $\mathrm{NaB}\left(\mathrm{C}_{6} \mathrm{H}_{5}\right)_{4}$ treatment and were easier to cleave and change into the amorphous phase by grinding. The mica ceramics with lower layer charges showed lower electrical resistance than those with higher layer charges in the low-temperature region but higher electrical resistance in the high-temperature region. The results of the electrical resistance can be explained by the concentrations of the lattice vacancy and $\mathrm{K}^{+}$ion in the interlayer. The dielectric loss tangent was influenced by the layer charge while the dielectric constant was almost unchanged. The chemical and physical properties of such micas are strongly dependent on the magnitude of the layer charge because the layer charge determines the interlayer bonding strength and the stability of mica structure.

\section{Keywords;}

Mica, Layer charge, Interlayer lattice vacancy, Interlayer bonding strength, Electrical properties 


\section{Introduction}

Mica ceramics are the typical machinable ceramics. The cleavage of fluorophlogopite crystals plays an important role in the machinability. In addition, K-type fluorophlogopite, of which the interlayer cation is potassium ion (K-fluorine micas), is excellent in thermal and chemical stability because it is structurally the most stable in the mica group. Moreover, it is important as an electrical insulator and dielectric. Mica demonstrating the basic structural formula of $\mathrm{X}_{0.5-1} \mathrm{Y}_{2-3} \mathrm{Z}_{4} \mathrm{O}_{10}(\mathrm{OH}, \mathrm{F})_{2}$ is a multicomponent system of alkaline or large alkaline earth ions X, small alkaline earth ions $\mathrm{Y}$ or aluminum in octahedral coordination $(\mathrm{Y})$ and $\mathrm{Z}$ ions, representing the sum of $\mathrm{Al}$ (III) and Si (IV) tetrahedral building blocks, as well as of oxygen, hydroxyl, and/or fluoride anions [1]. The layer charge of the synthetic K-fluorine micas has been shown to be a constant of $1.0 \mathrm{e} / \mathrm{Z}_{4} \mathrm{O}_{10}$ [2]. However, the layer charge should influence the chemical and physical properties of the micas because it controls the cation and lattice vacancy densities in the interlayer and hence determines the chemical bonding strength of the silicate layers [3].

In this study, synthesis of a series of K-fluorine micas having variable layer charges $\left[\mathrm{K}_{\mathrm{x}} \mathrm{Mg}_{3-\mathrm{x}} \mathrm{Li}_{\mathrm{x}}\left(\mathrm{Si}_{4} \mathrm{O}_{10}\right) \mathrm{F}_{2}\right.$, layer charge: $\left.\mathrm{x}=0.4-1.0 \mathrm{e} / \mathrm{Si}_{4} \mathrm{O}_{10}\right]$ was attempted, and the effect of the layer charge on the chemical and physical properties, (e.g., chemical reactivity, cleavability, electrical resistivity, dielectric and thermal expansion) of the obtained micas was investigated.

\section{Experimental procedure}

\subsection{Preparation of K- fluorine micas}

The reagents of $\mathrm{MgO}, \mathrm{Al}_{2} \mathrm{O}_{3}, \mathrm{SiO}_{2}$, $\mathrm{LiF}, \mathrm{KF}$ and $\mathrm{MgF}_{2}$ were mixed in the chemical 
compositions corresponding to $\mathrm{K}_{\mathrm{x}} \mathrm{Mg}_{3-\mathrm{x}} \mathrm{Li}_{\mathrm{x}}\left(\mathrm{Si}_{4} \mathrm{O}_{10}\right) \mathrm{F}_{2}(\mathrm{x}=0.4,0.6,0.8$ and 1.0). The mixtures were melted in a sealed platinum container at $1430^{\circ} \mathrm{C}$ for $2 \mathrm{~h}$, cooled at a rate of $5{ }^{\circ} \mathrm{C} / \mathrm{min}$, and then removed from the electric furnace at $800^{\circ} \mathrm{C}$. In this way, lumps of large mica crystals were obtained. The lumps were then ground into mica powders.

In addition, the mixtures of the raw materials mentioned above were melted in a sealed platinum container at $1450-1480^{\circ} \mathrm{C}$ for $1 \mathrm{~h}$. The melts were rapidly cooled outside of the furnace. The obtained glasses were re-heated at $1000^{\circ} \mathrm{C}$ for $4 \mathrm{~h}$ to form mica polycrystals (mica ceramics).

Crystalline phases in the mica powders and mica ceramics were analyzed using X-ray diffractometry (XRD), and the lattice constants of the micas were determined. In addition, infrared absorption spectra (IR spectra) of the micas were measured. Large mica crystals were sorted out from the mica powders by a wet classification method, ground $<45 \mu \mathrm{m}$ and then dissolved in an $\mathrm{HF}^{-\mathrm{HClO}_{4}}$ solution. Using the obtained solution, the $\mathrm{K}^{+}$content in the micas was analyzed using flame photometry. The fracture surfaces of the mica ceramics were observed using scanning electron microscopy (SEM).

\subsection{Estimation of properties of $\mathrm{K}$ - fluorine micas}

The mica powders with the size of $150-250 \mu \mathrm{m}$ were reacted with $\mathrm{NaB}\left(\mathrm{C}_{6} \mathrm{H}_{5}\right)_{4}$ (NaTPB) solution under a rigorous stirring [4]. After the reaction proceeded for fixed times, the reaction rate was determined from the diffraction intensity ratios of unreacted micas (K-fluorine micas) to products (Na-fluorine micas) in the XRD patterns.

After the mica powders were ground for fixed times, XRD profiles of (00l) of the micas were measured to examine the change in the crystallinity. Using mica suspensions, which were obtained by the water elutriation of the mica powders, self-supporting films 
of the micas were formed on the surface of a 100-mesh sieve. Cleavability of the micas was estimated from the formation of the self-supporting films, and the aspect ratio of the mica flakes was measured using SEM.

Specific electrical resistance $(\rho)$ of the mica ceramics was measured at $100-500^{\circ} \mathrm{C}$ by the two-probe method using a high insulation meter. Dielectric constant $(\varepsilon)$ and loss tangent $(\tan \delta)$ of the mica ceramics were measured using an impedance analyzer. Thermal expansion coefficient of the mica ceramics was measured using a dilatometer.

\section{Results and discussion}

\subsection{Crystal structure of micas having variable layer charges}

For the mica powders, the relationship between theoretical layer charge and experimentally obtained layer charge which was estimated from the $\mathrm{K}^{+}$content is shown in Fig. 1. The experimentally obtained layer charges corresponded to the theoretical layer charges. This means that a series of the micas having variable layer charges $(\mathrm{x}=0.4-1.0)$ was obtained.

Lattice constants of the mica powders are shown in Table 1. As the layer charge decreased, the lattice constants $\mathrm{a}$ and $\mathrm{b}$ increased while $\mathrm{c}$ decreased. The $\beta$ was almost constant. Such variations of the lattice constants resulted from change in distortion of the tetrahedral and octahedral sheets of the micas $[5,6]$. That is, as the layer charge decreases, the effective negative charge of apical oxygens $\left(\mathrm{O}_{\mathrm{a}}\right)$ in the tetrahedral sheet decreases, leading to lowering the repulsion between $\mathrm{O}_{\mathrm{a}}$ and basal oxygens $\left(\mathrm{O}_{\mathrm{b}}\right)$. As the results, the bonding angle of $\mathrm{O}_{a}-\mathrm{Si}-\mathrm{O}_{b}$ was reduced and the distance of $\mathrm{O}_{b}-\mathrm{O}_{b}$ was lengthened, indicating that the lattice constant $\mathrm{c}$ and the basal spacing $\mathrm{c} \cdot \sin \beta$ were shortened while the $\mathrm{a}$ and $\mathrm{b}$ were lengthened. 
IR spectra of the mica powders are shown in Fig. 2. As the layer charge decreased, the absorption band of Si- $\mathrm{O}_{\mathrm{a}}\left(\mathrm{a}_{1}^{\mathrm{B1}}\right)$ [7] was shifted to a lower wavenumber and that of $\mathrm{Si}-\mathrm{O}_{\mathrm{b}}\left(\mathrm{e}_{1}^{\mathrm{B} 1}\right)$ [7] was shifted to higher wavenumber. These results indicate that though the chemical composition of the tetrahedral sheet did not change, a stretching vibration of Si-O was markedly influenced by the layer charge. This change in the stretching vibration of Si-O was caused by the distortion of the tetrahedral sheet mentioned above.

Crystallinities of all the mica ceramics having variable layer charges were $100 \%$. Moreover, IR spectra of all the mica ceramics were almost identical as those in Fig. 2. These results mean that the layer charges of micas precipitated in the mica ceramics corresponded to the theoretical layer charges; that is, a series of the mica ceramics having variable layer charges of $\mathrm{x}=0.4-1.0$ was obtained. SEM photographs of fracture surfaces of the mica ceramics having variable layer charges are shown in Fig. 3. In the mica ceramic with $\mathrm{x}=1.0$, it was difficult to control the crystallization because the mica crystals precipitated rapidly and grew during the heating at $1000^{\circ} \mathrm{C}$. This lead to the mica ceramics composed of oriented mica particles $>100 \mu \mathrm{m}$. As the layer charge decreased, the precipitation and growth rates of mica crystals became relatively slow. Consequently, in the mica ceramic with $\mathrm{x}=0.8$, the orientation of the mica particles was not observed while mica particles grew up to $10-50 \mu \mathrm{m}$. The mica ceramics with $\mathrm{x}=0.4$ and 0.6 exhibited the microstructure consisting of randomly arranged mica flakes with size of $5-20 \mu \mathrm{m}$. Further, in the case of the mica ceramic with $\mathrm{x}=0.4$, there was a possibility of precipitation of a very small amount of $\mathrm{Mg}_{2} \mathrm{SiO}_{4}$. The trace was observed in the XRD pattern.

\subsection{Chemical and physical properties}

(1) Chemical and crystallographic properties 
Reaction between K-fluorine mica and NaTPB proceeds according to the following equation [4];

$$
\text { K-fluorine mica }+\mathrm{NaB}\left(\mathrm{C}_{6} \mathrm{H}_{5}\right)_{4} \rightarrow \text { Na-fluorine mica }+\mathrm{KB}\left(\mathrm{C}_{6} \mathrm{H}_{5}\right)_{4} \downarrow
$$

In order to determine the reactivity of K-fluorine micas having variable layer charges, the X-ray diffraction intensity ratios (Ir) of unreacted micas (K-fluorine micas) to products (Na-fluorine micas) were calculated according to the following equation;

$$
\operatorname{Ir}=\mathrm{I}_{\mathrm{Na}} /\left(\mathrm{I}_{\mathrm{Na}}+\mathrm{I}_{\mathrm{K}}\right)
$$

where $I_{\mathrm{Na}}$ and $\mathrm{I}_{\mathrm{K}}$ are X-ray diffraction intensities of the (001) plane of Na-fluorine micas and the (001) plane of K-fluorine micas, respectively. The relationship between reaction time and Ir is shown in Fig. 4. This figure shows that the reaction of the micas having lower layer charges proceeded more rapidly. The reaction of the mica with $\mathrm{x}=0.4$ was almost completed in 20 min while that of the mica with $\mathrm{x}=1.0$ proceeded only slightly. The decrease in the layer charge means an increase in the population of vacancies in the interlayer. Consequently, the migration of $\mathrm{K}^{+}$ion became easier in the interlayer of the micas having lower layer charges such that the reactivity of the micas having lower layer charges increased. On the other hand, using the mica powder with $x=1.0$, which was ground still more to $<45 \mu \mathrm{m}$, the reaction between it and $\mathrm{NaB}\left(\mathrm{C}_{6} \mathrm{H}_{5}\right)_{4}$ solution was completed in $3 \mathrm{~h}$. This indicates that the reaction depended not only on the layer charge but also on the particle size. The large difference in the reactivity between the micas with $\mathrm{x}=0.6$ and 0.8 might result from the slight difference in the particle size distributions of these micas.

Crystallite sizes (thickness in the vertical direction relative to the layer) of the mica powders were measured from the line broadening of the diffraction of (005) plane according to the Scherrer equation. The relationship between the grinding time and the crystallite size is shown in Fig. 5. The (005) profile tended to become weaker with a 
decrease in the layer charge. The diffractions of the mica with $x=0.4$ disappeared after grinding for $15 \mathrm{~min}$, and the mica became amorphous. The crystallite size of the micas with $\mathrm{x}=0.8$ and 1.0 did not change after $20 \mathrm{~min}$, but the diffraction intensities became smaller with further grinding, which means that the mica crystals became partially amorphous. In contrast, however, the crystallite size of the mica with $\mathrm{x}=0.6$ decreased even after $20 \mathrm{~min}$, which indicates that the cleavage of the mica with $\mathrm{x}=0.6$ was easier than that of the micas with $\mathrm{x}=0.8$ and 1.0. Furthermore, at the same time, the partial transition to amorphous also proceeded.

The micas with the size of 150 to $250 \mu \mathrm{m}$ were sorted out from the mica powders by a wet classification. While the aspect ratio of the sorted-out micas with $\mathrm{x}=1.0$ and 0.8 was $\sim 8$, that of the mica with $\mathrm{x}=0.6$ was $\sim 20$. Only the mica with $\mathrm{x}=0.6$ formed the self-supporting film, as shown in Fig. 6. As the layer charge decreased, the interlayer bonding strength between silicate layers became weaker and the micas became easier to be cleaved thinly, which resulted in the formation of the self-supporting film. The mica with $\mathrm{x}=0.4$ was cleaved very thinly and flakes with aspect ratio of 40 were observed. However, the amount of such mica flakes was few. Many mica crystals with $\mathrm{x}=0.4$ were finely powdered because the crystallinity was inferior to that of other micas. Thus the mica with $x=0.6$ having both high cleavability and high crystallinity resulted in high yield of the mica flakes with higher aspect ratios.

(2) Electrical properties

For the mica ceramics with $\mathrm{x}=0.6$ and 0.8 , the relationship between $\rho$ and inverse of temperature $(1 / \mathrm{T})$ is shown in Fig. 7. The two $\rho$ vs. 1/T curves were divided into two regions at about $300^{\circ} \mathrm{C}$. These low and high temperature regions might correspond to extrinsic and intrinsic regions, respectively. For single crystal of K-fluorine mica (fluorophlogopite) with $\mathrm{x}=1.0$, the $\rho$ of the vertical direction relative to the layer $(\rho \perp)$ is 
larger than that of the parallel direction relative to the layer $(\rho \|)[8]$. The $\rho \perp$ of the single crystal was $10^{2}-10^{3}$ times as large as the $\rho$ of the mica ceramic with $\mathrm{x}=0.8$ at $120-300^{\circ} \mathrm{C}$ and $10^{3}-10^{4}$ times at $>300^{\circ} \mathrm{C}$. On the other hand, the $\rho \|$ of the single crystal, . which was measured at $120-300^{\circ} \mathrm{C}$, was almost the same order of magnitude as the $\rho$ of the mica ceramic with $\mathrm{x}=0.8$ at $120-300^{\circ} \mathrm{C}$. That is, the electrical conductivity of the mica ceramics is explained by the existence of highly conductive paths, namely the interlayer region of mica and the grain boundary between the micas. The $\rho$ of the mica ceramic with $\mathrm{x}=0.6$ was lower than that of the mica ceramic with $\mathrm{x}=0.8$ in the low-temperature region; however, the former was higher than the latter in the high-temperature region. For natural biotite micas, Guseinov observed a wide range of electrical conductivity values, covering five orders of magnitude at $200^{\circ} \mathrm{C}$ and four orders of magnitude at $500^{\circ} \mathrm{C}$ [9]. He explained this fact as follows [9]; the wide range variations in biotite composition, caused by isomorphic substitutions, produce the wide range of conductivity values, particularly, the effect of impurities on conductivity is enhanced at low temperatures. However, at high temperatures, when the conductivity is controlled by intrinsic defects, the range of conductivity is narrowed. In this study, the chemical composition of the synthetic micas was controlled ideally and the layer charge was varied. Because the interlayer vacancy increased with a decrease in the layer charge, the diffusion of $\mathrm{K}^{+}$ion became easier in the interlayer. That is, in the low-temperature region, the conductivity was predominantly controlled by the vacancy concentration, and, therefore, the electrical resistance of the mica ceramics with lower layer charge became higher. However, the conductivity in the high-temperature region depended predominantly on the carrier $\left(\mathrm{K}^{+}\right.$ion) concentration. Thus the resistance of the mica ceramics with higher layer charge became lower at the high temperatures.

The $\varepsilon$ and $\tan \delta$ of the mica ceramics are shown in Fig. 8. The $\varepsilon$ was not affected by 
the layer charge while the tan $\delta$ increased with a decrease in the layer charge in the range of $x=0.6-1.0$. Such an increase in the tan $\delta$ is related to the relaxation which occurred by the jump of the $\mathrm{K}^{+}$ions in the interlayer [10] because the vacancy increases with a decrease in the layer charge. The influence of the electrical conductivity on the $\tan \delta$ might be ignored because the tan $\delta$ was measured at the high frequency of $1 \mathrm{MHz}$ in this study. The space-charge polarization and dipole moment originating from the association between the $\mathrm{K}^{+}$ions and vacancy affect the $\varepsilon$; however, these phenomena do not appear at room temperature [10]. Therefore, the $\varepsilon$ is determined by ionic polarization and electronic polarization [10], and consequently, it was not influenced by the layer charge in this study.

(3) Thermal expansion

Thermal expansion coefficients of the mica ceramics with $\mathrm{x}=1.0$ and 0.4 were $5.9 \times$ $10^{-6} /{ }^{\circ}$ and $4.8 \times 10^{-6} /{ }^{o}$, respectively, in the temperature range of room temperature to $300^{\circ} \mathrm{C}$. The thermal expansion coefficient decreased with a decrease in the layer charge. The single crystal of K-fluorine mica (fluorophlogopite) has anisotropic thermal expansion coefficients [11]. The thermal expansion of the vertical direction relative to the layer is larger than that of the parallel direction relative to the layer. The lattice vibration caused by heating might be relaxed due to the space formed by the vacancies in the interlayer. Therefore, the thermal expansion coefficients of directions of $a, b$ and $c$ axes for the mica crystals with lower layer charges became lower. The K-fluorine mica ceramics synthesized in this study have lower thermal expansion coefficients because of the nature of tetrasilicic mica [12]. 


\section{Conclusions}

In this study, $\mathrm{K}$-fluorine mica $\left(\mathrm{K}_{\mathrm{x}} \mathrm{Mg}_{3-\mathrm{x}} \mathrm{Li}_{\mathrm{x}}\left(\mathrm{Si}_{4} \mathrm{O}_{10}\right) \mathrm{F}_{2}\right)$ powders and ceramics having variable layer charges $(\mathrm{x}=0.4-1.0)$ were synthesized. The influence of the layer charge on the chemical and physical properties of the micas were investigated.

As the layer charge decreased, which means that the interlayer vacancy increases, the $\mathrm{K}^{+}$ions became easier to move in the interlayer. Consequently, as the layer charge decreased, the reactivity between the micas and $\mathrm{NaB}\left(\mathrm{C}_{6} \mathrm{H}_{5}\right)_{4}$ became higher, and the electrical resistance became lower at the low-temperature range. On the other hand, the conductivity at the high-temperature region depended predominantly on the carrier $\left(\mathrm{K}^{+}\right.$ ion) concentration. Thus the resistance of the mica ceramics with higher layer charge became lower at high temperatures. The dielectric constant was not affected by the layer charge while the loss tangent increased with a decrease in the layer charge in the range of $x=0.6-1.0$. Such an increase in loss tangent was caused by the relaxation which occurred by the jump of the $\mathrm{K}^{+}$ions in the interlayer due to the increase in the interlayer vacancy. In addition, as the layer charge decreased, interlayer bonding strength between silicate layers became lower. The decrease in the interlayer bonding strength and the increase in the interlayer vacancy caused the high cleavability, low stability against grinding and low thermal expansibility. 


\section{Acknowledgement}

The authors would like to thank Mr. Tatsumi Maegasako and Mr. Katsuhiro Imamura for their experimental support. 


\section{References}

1. W. Höland and G. Beall, in "Glass-Ceramic Technology" (The American Ceramic Society, Westerville, Ohio, 2002) p.124.

2. H. Kodama, G. J. Ross, J. T. Iiyama and J. L. Robert, Am. Mineral., 59 (1974) 491.

3. R. F. Giese Jr., Clays Clay Minerals, 25 (1977) 102.

4. K. Kitajima and N. Daimon, J. Chem. Soc. Japan, (1974) 680.

5. H. Toraya, S. Iwai, F. Marumo and M. Hirao, Z. Kristallogr., 148 (1978) 65.

6. Y. Ihara and K. Kitajima, J. Ceram. Soc. Japan, 105 (1997) 881.

7. K. Kitajima and N. Takusagawa, Clay Minerals, 25 (1990) 235.

8. I. Tate, K. Kitajima and N. Daimon, Kougyou Kagaku (J. Chem. Soc. Japan), 71 (1968) 976.

9. A. A. Guseinov, Izvestiya Phys. Solid Earth, 34 (1998) 382.

10. W. D. Kingery, H. K. Bowen and D. R. Uhlmann, in "Introduction to Ceramics" (John Wiley \& Sons, New York, 1976) p.937.

11. K. Kitajima, Kougyou Kagaku (J. Chem. Soc. Japan), 74 (1971) 1792.

12. H. R. Shell and K. H. Ivey, in "Fluorine Micas, U. S. Bur. Mines. Bull. 647" (U. S. Dept. of the Int, Washington, D. C., 1969) p.243. 
Table I Lattice constants of the mica powders having variable layer charges

\begin{tabular}{c|ccccc}
\hline layer charge & \multicolumn{5}{|c}{ lattice constant $/ \AA$} \\
$\mathrm{x}$ & $\mathrm{a}$ & $\mathrm{b}$ & $\mathrm{c}$ & $\beta$ & $\mathrm{csin} \beta$ \\
\hline 1.0 & $5.237(2)$ & $9.064(2)$ & $10.150(2)$ & $99.91(3)$ & $9.999(2)$ \\
0.8 & $5.239(2)$ & $9.074(3)$ & $10.143(2)$ & $99.92(3)$ & $9.992(2)$ \\
0.6 & $5.243(2)$ & $9.084(2)$ & $10.136(3)$ & $99.90(3)$ & $9.985(3)$ \\
0.4 & $5.251(2)$ & $9.092(2)$ & $10.129(3)$ & $99.93(3)$ & $9.977(3)$ \\
\hline
\end{tabular}

Standard deviation is in parentheses. 


\section{Figure legends}

Fig. 1. The relationship between theoretical layer charge (dotted line) and experimentally obtained layer charge $(\bullet)$.

Fig. 2. IR spectra of the mica powders having variable layer charges. Layer charge (x) $=$ (a) 1.0 , (b) 0.8 , (c) 0.6 and (d) 0.4 .

Fig. 3. SEM photographs of fracture surfaces of the mica ceramics having variable layer charges. Layer charge $(x)=(a) 1.0,(b) 0.8$, (c) 0.6 and (d) 0.4 .

Fig. 4. The relationship between reaction time and reaction rate. Layer charge $(\mathrm{x})=$ $(\Delta): 1.0,(\square): 0.8,(\bullet): 0.6$ and $(\circ): 0.4$. The reaction rate was represented by the relative diffraction intensity (Ir). $\mathrm{Ir}=\mathrm{I}_{\mathrm{Na}} /\left(\mathrm{I}_{\mathrm{Na}}+\mathrm{I}_{\mathrm{K}}\right)$, $\mathrm{I}_{\mathrm{K}}$ : diffraction intensity of (001) of K-fluorine micas, and $\mathrm{I}_{\mathrm{Na}}$ : diffraction intensity of (001) of Na-fluorine micas.

Fig. 5. The relationship between grinding time and crystallite size of the micas having variable layer charges. Layer charge $(\mathrm{x})=(\circ): 1.0,(\Delta): 0.8$ and $(\square)$ : 0.6.

Fig. 6. Photograph of the self-supporting film obtained from thin flakes of the mica having layer charge of 0.6 .

Fig. 7. The temperature dependency of electrical resistance of the mica ceramics having variable layer charges. Layer charge $(\mathrm{x})=(\bullet)$ : 0.8 and $(\circ)$ : 0.6.

Fig. 8. Dielectric constant $(\varepsilon: \bullet)$ and loss tangent $(\tan \delta: \circ)$ plotted against the layer charge $(\mathrm{x})$ of the mica ceramics having variable layer charges. 


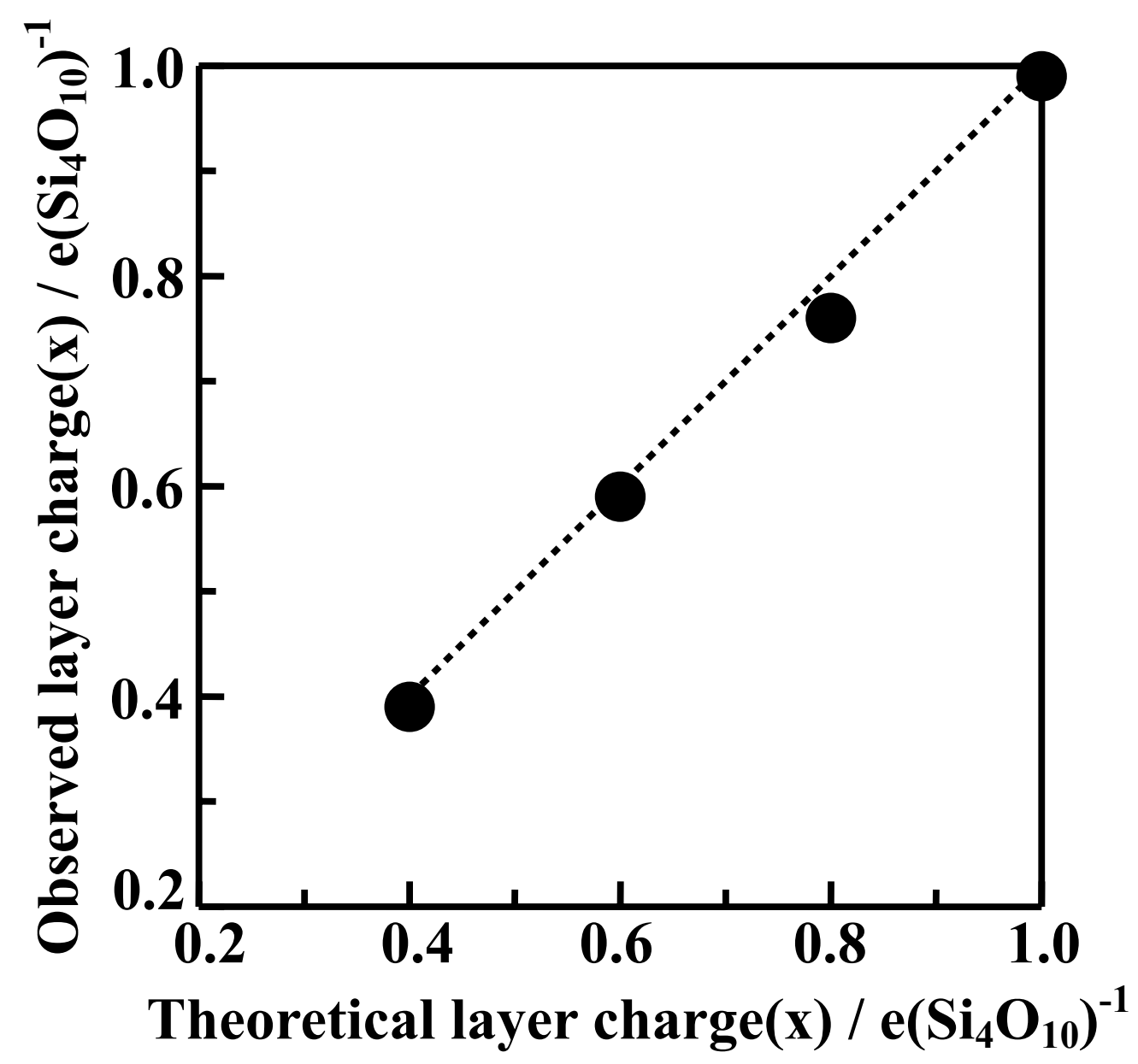

Fig. 1. The relationship between theoretical layer charge (dotted line) and experimentally obtained layer charge $(\bullet)$. 


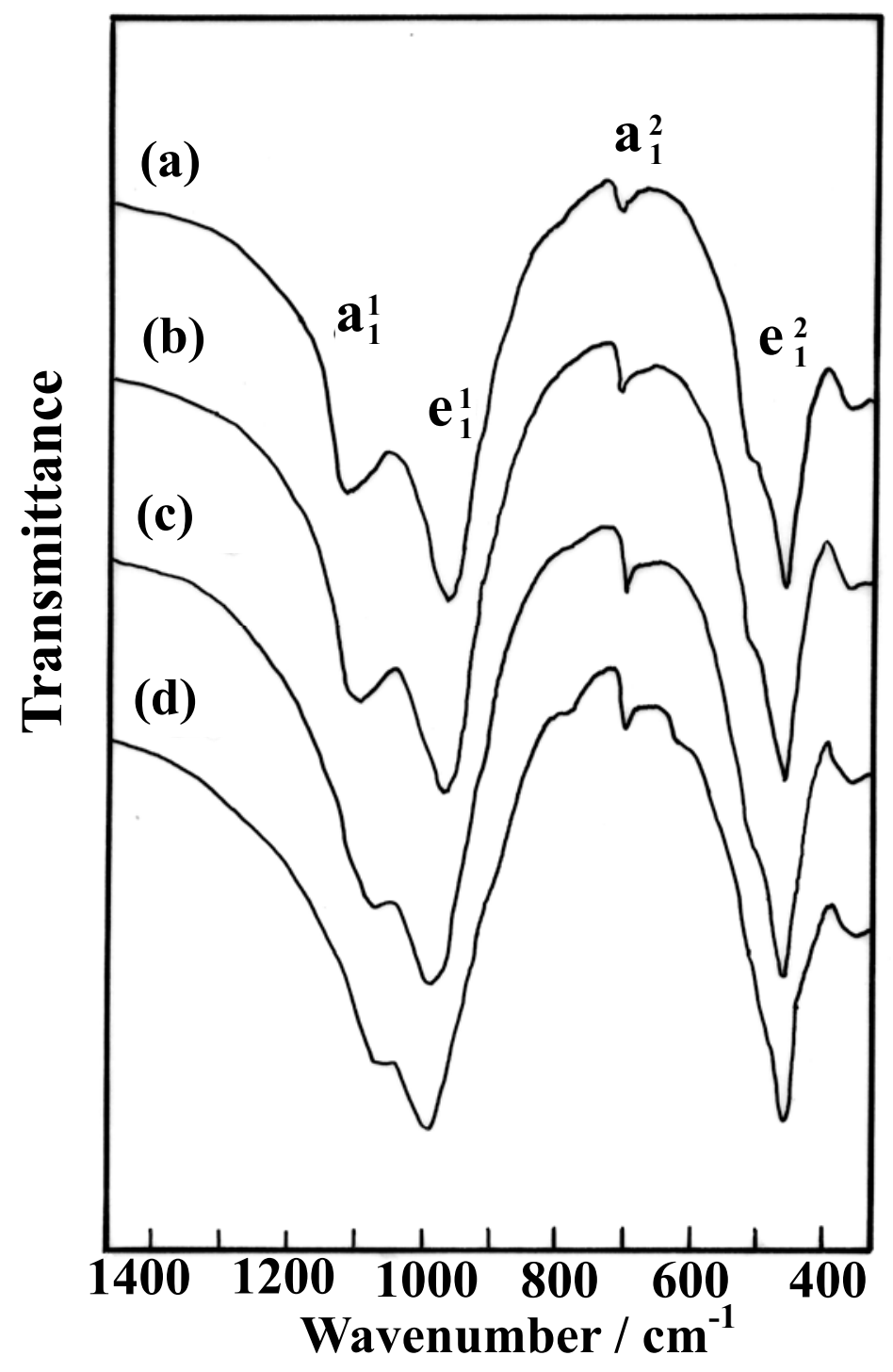

Fig. 2. IR spectra of the mica powders having variable layer charges. Layer charge (x)= (a) 1.0, (b) 0.8 , (c) 0.6 and (d) 0.4 

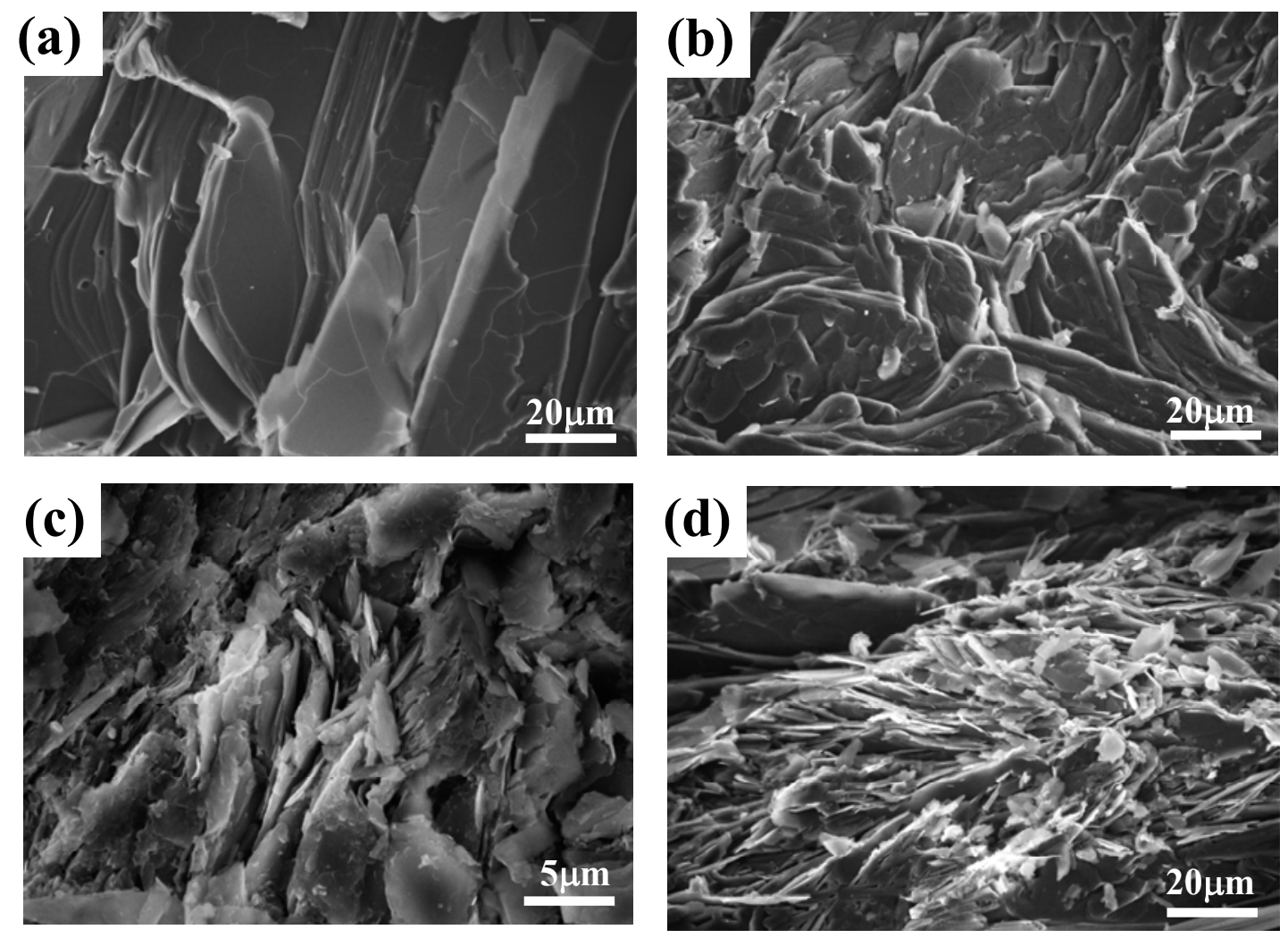

Fig. 3. SEM photographs of fracture surfaces of the mica ceramics having variable layer charges. Layer charge $(x)=(a) 1.0$, (b) 0.8 , (c) 0.6 and (d) 0.4 . 


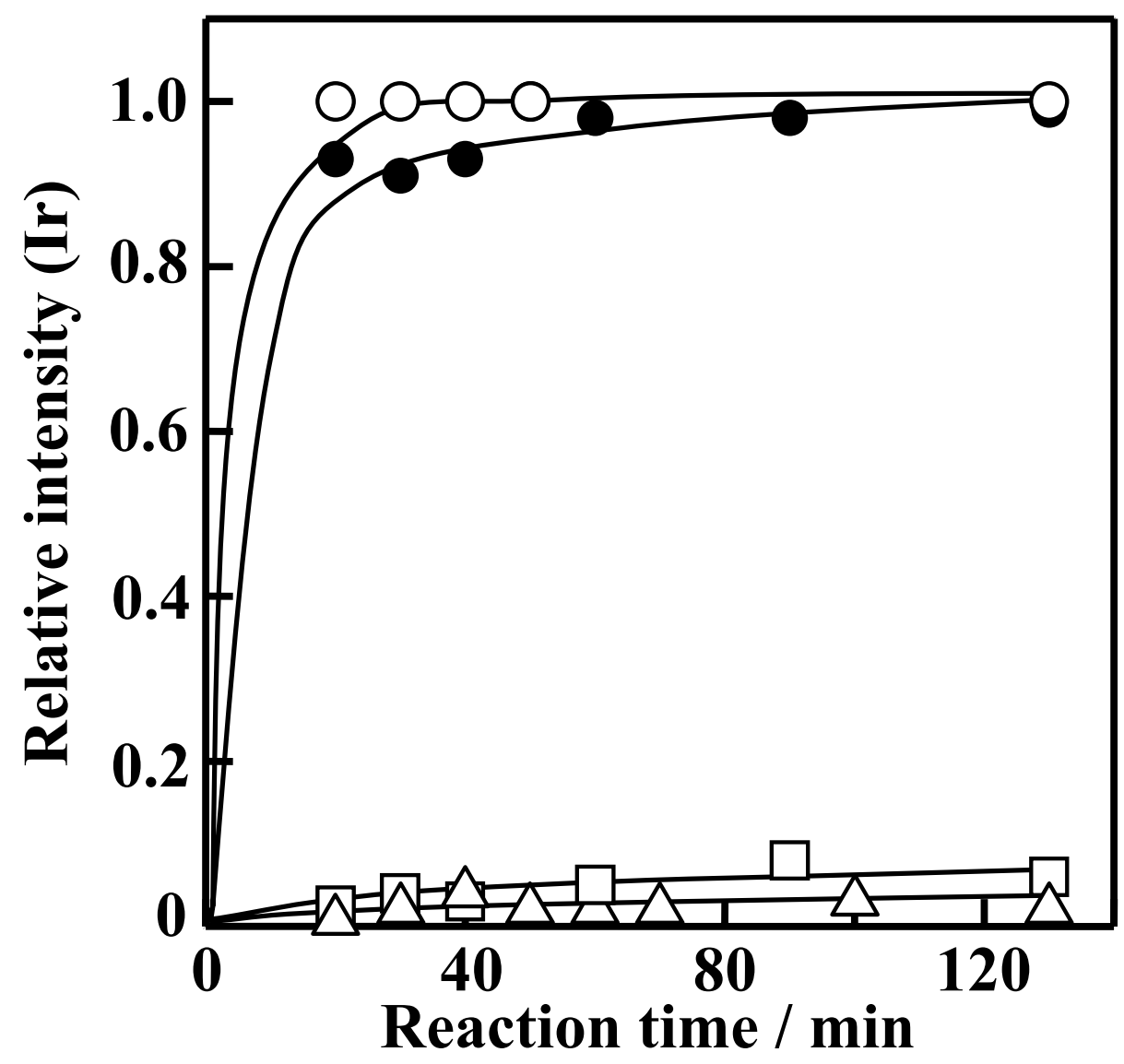

Fig. 4. The relationship between reaction time and reaction rate. Layer charge $(\mathrm{x})=(\Delta): 1.0,(\square): 0.8,(\bullet): 0.6$ and $(\circ)$ : 0.4 . The reaction rate was represented by the relative diffraction intensity $(\mathrm{Ir}) . \mathrm{Ir}=\mathrm{I}_{\mathrm{Na}} /\left(\mathrm{I}_{\mathrm{Na}}\right.$ $\left.+\mathrm{I}_{\mathrm{K}}\right), \mathrm{I}_{\mathrm{K}}$ : diffraction intensity of (001) of $\mathrm{K}$-fluorine micas, and $\mathrm{I}_{\mathrm{Na}}$ : diffraction intensity of (001) of Na-fluorine micas. 


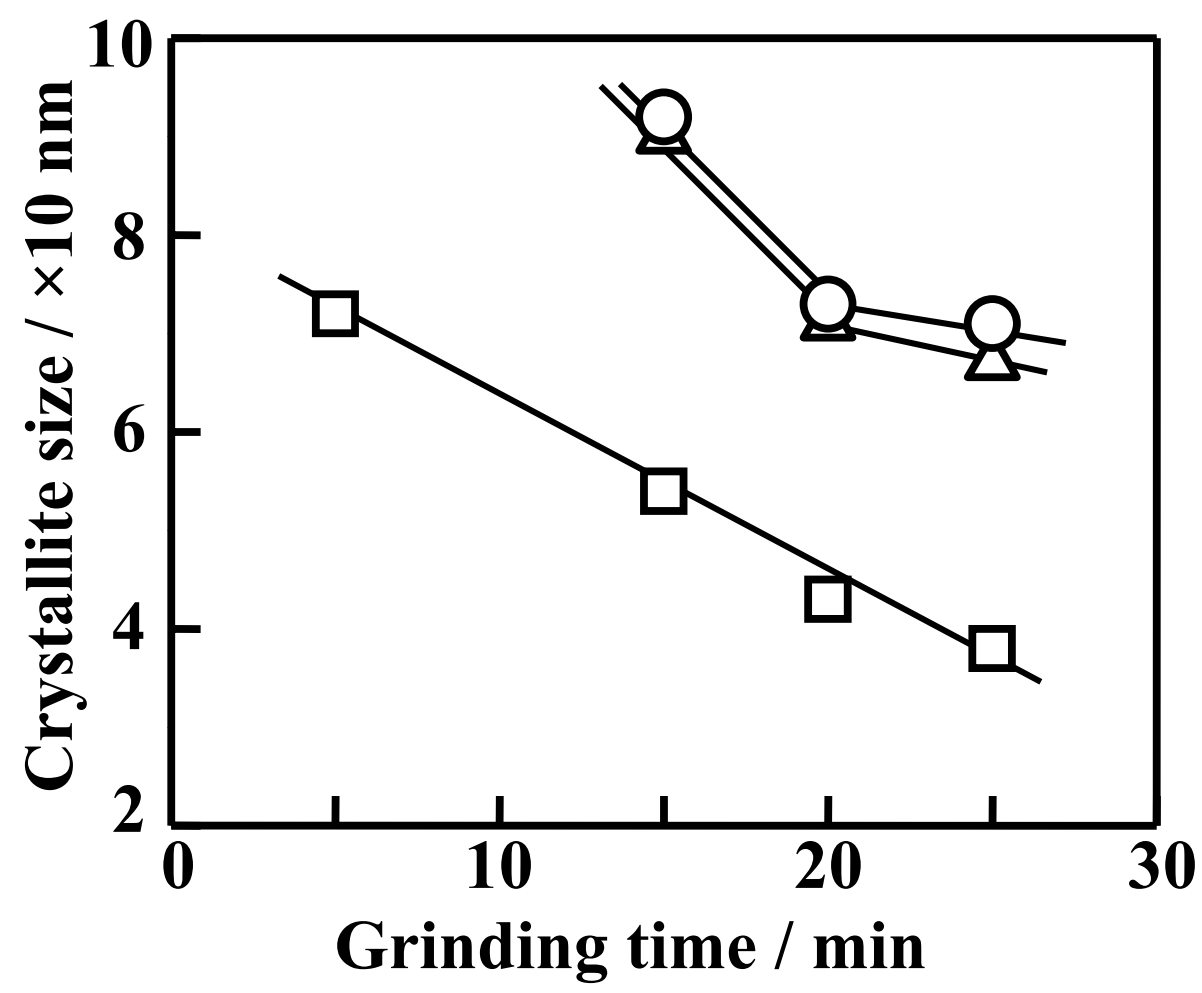

Fig. 5. The relationship between grinding time and crystallite size of the micas having variable layer charges. Layer charge $(\mathrm{x})=(0): 1.0,(\Delta): 0.8$ and (口): 0.6. 


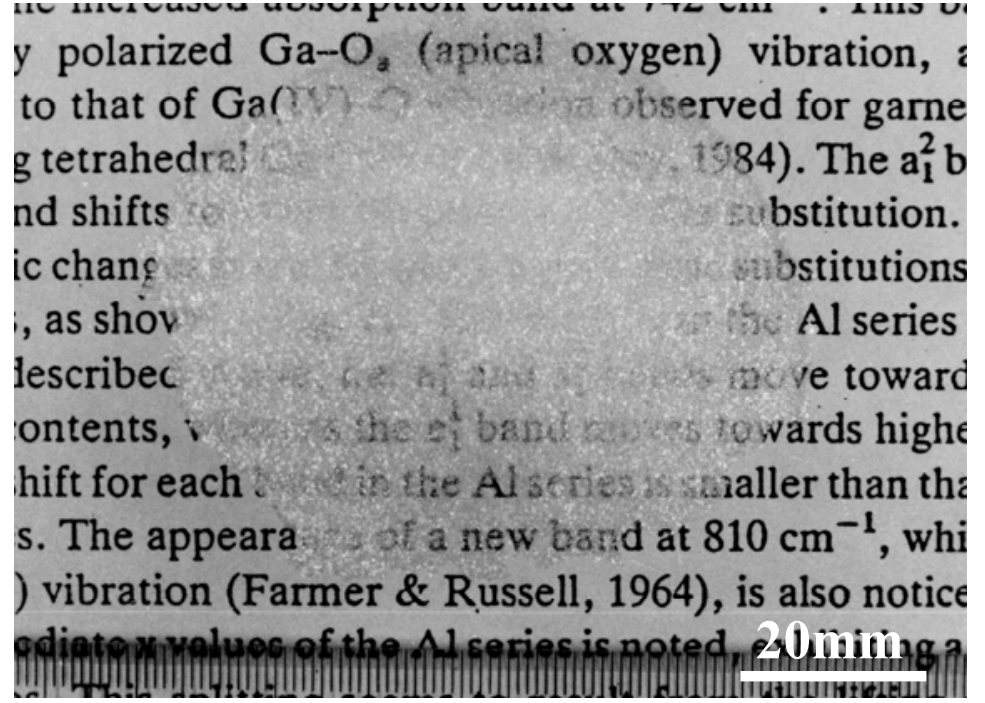

Fig. 6. Photograph of the self-supporting film obtained from thin flakes of the mica having layer charge of 0.6. 


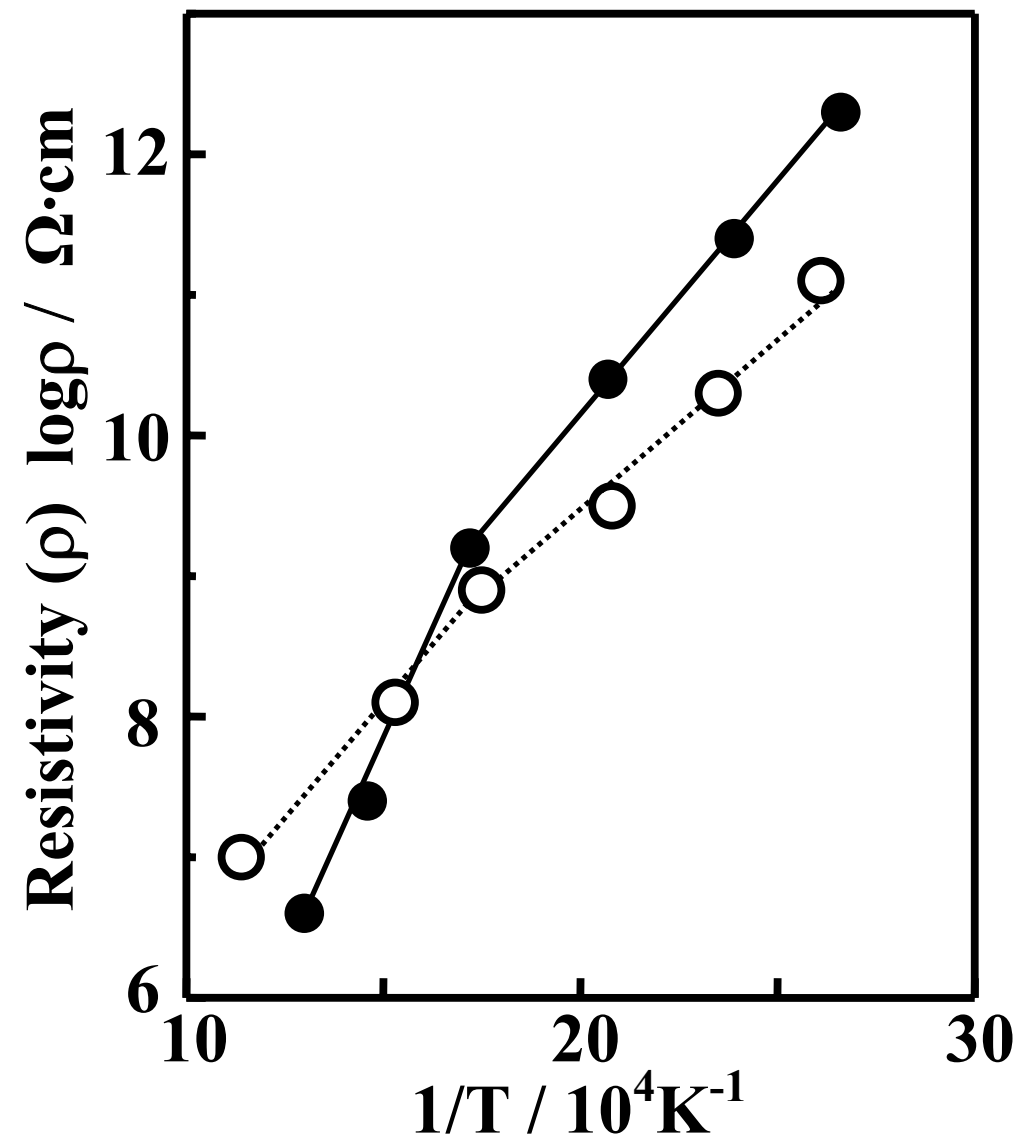

Fig. 7. The temperature dependency of electrical resistance of the mica ceramics having variable layer charges. Layer charge $(\mathrm{x})=(\bullet)$ : 0.8 and $(\mathrm{O})$ : 0.6. 


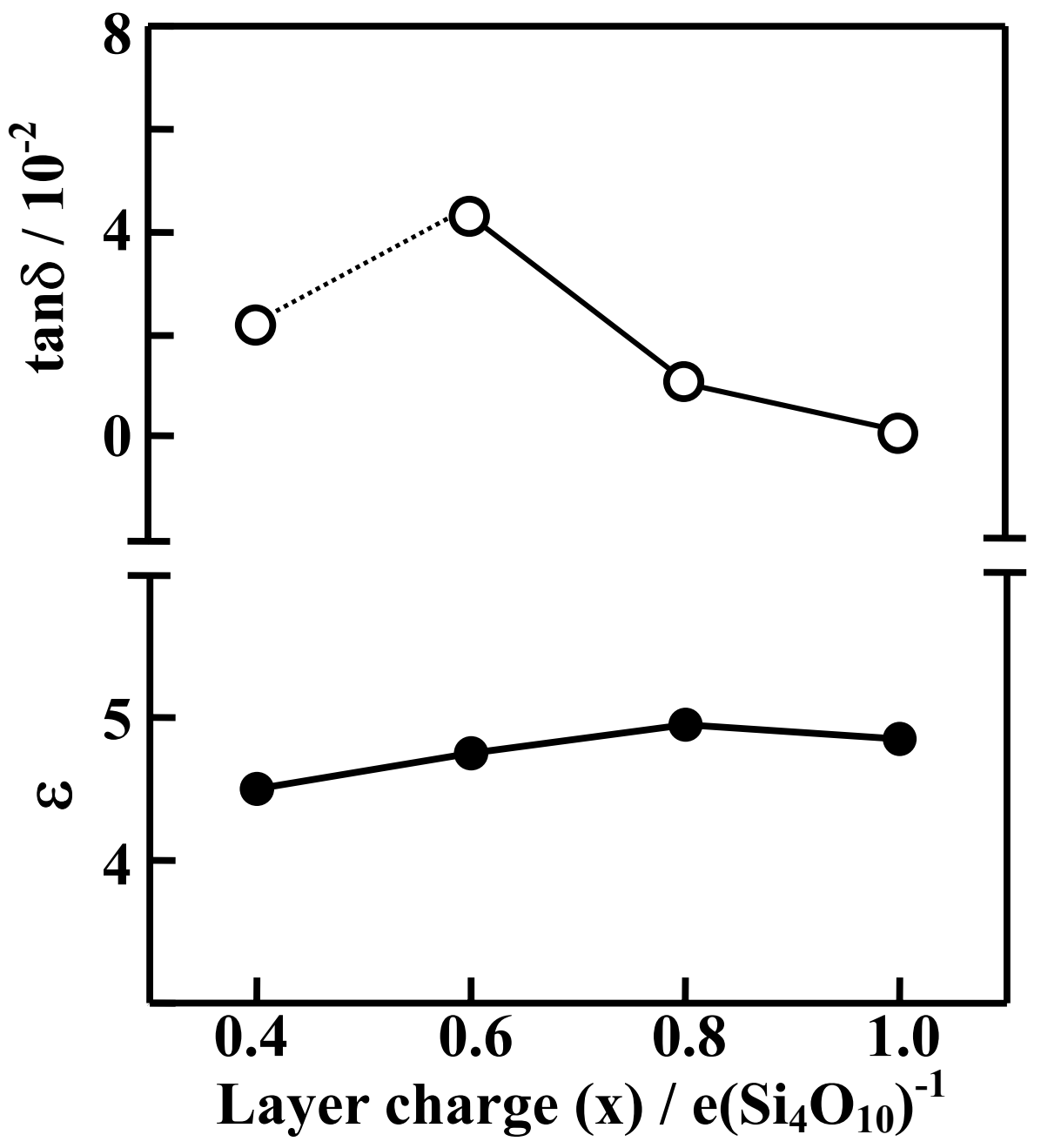

Fig. 8. Dielectric constant $(\varepsilon: \bullet)$ and loss tangent $(\tan \delta: \circ)$ plotted against the layer charge $(\mathrm{x})$ of the mica ceramics having variable layer charges. 